\title{
Kronik Böbrek Yetmezliği Hastalarının Glomerüler Filtrasyon Değerinin Bağımsız Değişkenler ile Yordama Gücü
}

\author{
Predictability of Glomerular Filtration Value of Chronic Renal Failure \\ Patients with Independent Variables
}

\author{
Özlem Doğu Kökcüi ${ }^{1}$, Döndü Sevimli Güler ${ }^{2}$, Savaş Sipahi ${ }^{3}$, Kenan Evren Öztop ${ }^{4}$ \\ ${ }^{1}$ Sakarya Üniversitesi Sağlık Bilimleri Fakültesi, Ebelik Bölümü, Sakarya, Türkiye \\ ${ }^{2}$ Sakarya Üniversitesi Eğitim ve Araştırma Hastanesi, Eğitim Koordinatörlüğü, Sakarya, Türkiye \\ ${ }^{3}$ Sakarya Üniversitesi Eğitim ve Araştırma Hastanesi, Nefroloji Ana Bilim Dalı, Sakarya, Türkiye \\ ${ }^{4}$ Sakarya Özel Nefromed Diyaliz Merkezi, Sakarya, Türkiye \\ Yazıșma Adresi / Correspondence: \\ Özlem Doğu Kökcü
}

Sakarya Üniversitesi Sağlık Bilimleri Fakültesi, Ebelik Bölümü, Esentepe Kampüs, 54187, Sakarya, Türkiye

T: +90505679 2063 E-mail: : doguozlem@hotmail.com।

Geliş Tarihi / Received : 28.03.2019 Kabul Tarihi / Accepted : 25.07.2019

Orcid :

Özlem Doğu Kökcü https://orcid.org/0000-0003-1257-2551

Döndü Sevimli Güler https://orcid.org/0000-0003-2618-4920

Savaş Sipahi https://orcid.org/0000-0002-4293-4341

Kenan Evren Öztop https://orcid.org/0000-0002-7694-8354

\footnotetext{
$\ddot{\mathrm{O} z}$

Amaç Çalışma, hemodiyaliz hastalarının hastane anksiyete-depresyon düzeyi, uyku kalitesi ve öğrenim gereksinimlerinin, glomerular filtrasyon değeri (GFR) üzerindeki ilișkisini araștırmak amacıyla yapıldı. ( Sakarya Tip Dergisi 2019, 9(3):412-419 )

Gereç ve Tanımlayıcı ve ilișki arayıcı tipindeki bu çalıșmanın evrenini Sakarya’ da bir eğitim ve araștırma hastanesinde nefroloji ve diyaliz ünitelerinde tedavi gören tüm hastalar, Yöntemler örneklemini ise araştırmanın sınılıllılarına uyan 218 hasta oluşturdu. GFR değeri doğrultusunda diyalize giren ve girmeyen gruplar belirlendi. İstatistiksel analizlerde SPSS 21 programı kullanildı.

Bulgular Çalısma sonucunda hastaların 15>GFR olan bireylerin \%21.7'sinde anksiyete, \%39.1'inde depresyon eşik seviyesinin üzerinde iken, $15<$ GFR bireylerin \%91.3'ünde anskiyete, \%95.0'inda depresyon eșik seviyesinin üzerinde idi. Ögrenme gereksinimi toplam puan ortalamaları 15>GFR bireylerde $182.00-67.5$ ve $15<$ GFR bireylerde ise; 95.50-41.5 idi. Uyku skalası toplam puanına cut-off değeri olan 5 puanına göre baktı̆ı̆ıızda $15>$ GFR olan bireylerin $\% 85.5$ 'inin $(\mathrm{n}=118), 15<\mathrm{GFR}$ ise \%100'ünün uyku kalitesi kötü olduğu belirlendi. Varyans analizleri sonucu anskiyete-depresyon ile GFR düzeyi arasında ilişki olduğu ve birbirlerini \%50 tahmin ettiği belirlendi (p<0.001).

Sonuç Bu sonuçlar doğrultusunda diyaliz tedavisi gören bireylerin emosyonel problemlerinin değerlendirilmesi ve gerekli durumlarda psikiyatrik desteğin başlatılması önerilebilir.

Anahtar Kronik böbrek yetmezliği; glomerüler filtrasyon; uyku; anksiyete; depresyon; eğitim gereksinimleri. Kelimeler

Abstract

Objective The study was conducted to investigate the effects of hospital anxiety-depression level, sleep quality and learning needs on glomerular filtration value (GFR) of hemodialysis patients. ( Sakarya Med J 2019, 9(3):412-419)

Materials

The population of this descriptive and relationship seeker study was composed of all patients who were treated in nephrology and dialysis units in an education and research hospital in Sakarya, and sample consists of the patients that fit the limitations of the study. GFR values and groups with and without dialysis were identified. SPSS 21 was used for statistical analysis.

Results According to the results of the study; of patients with $15>$ GFR, anxiety was found to be over the threshold for $21.7 \%$, and depression for $39.1 \%$; of patients with $15<$ GFR, anxiety was found to be over the threshold for 91.3 , depression for $95.0 \%$. The learning needs total mean scores was 182.00-67.5 for $15>$ GFR individuals and $95.50-41.5$ for $15<G F R$ individuals. When the sleep scale scores are checked in terms of cut-off vale of $5,85.5 \%$ ( $n=118$ ) of individuals with $15>$ GFR and $100 \%$ of individuals with $15<$ GFR were found to have poor sleep quality. Analysis of variance showed that there is a relationship between the levels of anxiety-depression and GFR and that they predict each other by $50 \%(p<0.001)$.

Conclusion As the result of this study, it is suggested that evaluation of emotional problems of individuals who have dialysis treatment and initiation of psychiatric support for required cases should be provided.

Keywords Chronic renal failure; glomerular filtration; sleep; anxiety; depression; educational needs
} 


\section{GIIRIș}

Kronik Böbrek Yetmezliği (KBY) glomerüler filtrasyon hızı (GFR) azalmanın sonucu böbreğin sıvı-elektrolit dengesini ayarlama ve metabolik fonksiyonlarında ilerleyici bozulma hali olarak tanımlanır. KBY'de diyaliz tedavileri (periton diyalizi, hemodiyaliz), böbrek transplantasyonu gibi renal replasman tedavileri uygulanmaktadır. ${ }^{1-3}$ Uzun süren tedavi süreci ve yaşanan fiziksel semptomların yanı sıra bireylerin ruhsal ve sosyal hayatları da önemli ölçüde etkilenmektedir. Bu nedenle hasta birey mevcut patolojik duruma ek olarak psikiyatrik ve psikososyal sorunlar da yaşayabilmektedir. Çalışmalarda hastalık ve diyaliz tedavisi kaynaklı psikososyal problemlerin arttığı vurgulanmaktadır. Bireylerin fonksiyon durum ve bağımlılıkıbağımsızlık durumunun ciddi şekilde etkilendiği ve bu durumun tedaviye uyumu olumsuz etkilediği belirtilmektedir. ${ }^{3-6}$

Bireyin diyaliz tedavisine bağımlılığı, hastalıkla ilgili yaşadığı semptomlar, iş, gelir, sosyal aktivite ve aile ilişkilerinde yaşadığı kısıtlamalar anksiyete ve uyku problemleri yaşamasına neden olmaktadır. Bu faktörler ayrıca diyaliz hastalarında görülen depresif belirtilerin yüksek prevalansından da sorumludur. Yapılan çalışmalar, diyaliz hastalarında depresyonun hastaneye yatışta artış ve mortalite ile ilişkili olduğunu göstermektedir. ${ }^{3,7,8}$

KBY hastalarında uyku sorunları prevalansının; \%50-80 oranında olduğu bildirilmektedir., ${ }^{2,9,10}$ Diyaliz tedavisi ile ilişkili ağrı, yorgunluk, üremik sendrom ve anksiyete uyku problemi yaşamalarının başlıca sorumlusu olarak gösterilmektedir.,10,11 Uzun süre devam eden uyku bozukluğu genel sağlığın ve fonksiyonların bozulmasına neden olur ve bireylerin tedaviye yanıtını olumsuz etkiler. Bu nedenle uygulamalardaki temel amaç; uyku problemlerinin erken tanınması ve uyku kalitesinin iyileştirilmesi olmalıdır. ${ }^{10,12}$ Literatürde hemodiyaliz hastalarının eğitim seviyesinin yüksek oluşunun hastalık sürecine ve tedaviye uyumu olumlu etkilediği vurgulanmaktadır., ${ }^{6,13}$ Tedavi, komplikasyonlar ve semptomların yönetiminde, yaşam kalitesinin arttırılmasında, bilgi gereksinimlerinin önemli olduğu bi- linmektedir. Literatürde, hasta eğitimlerinin yapılması gerektiği, eğitimlerde sağlık profesyonellerine önemli roller düştüğü ve hasta eğitimleri ile ilgili kapsamlı araştırmalara gereksinim duyulduğu belirtilmektedir. ${ }^{14-16}$

Yapılan çalışmalarda sonucu KKY hastalarının yaşadıkları semptom ve tedavi süreci, bilgi durumunun yetersizliği, gelecek kaygısı gibi birçok neden emosyonel problemler yaşamalarına, uyku ve dolayısıyla yaşam kalitelerinin olumsuz etkilenmesine neden olmaktadır. Ancak literatürde, GFR düzeyine göre bireyleri değerlendiren çok fazla çalışmaya rastlanmadı. Bu doğrultuda çalışma, diyaliz tedavisi uygulanan ve uygulanmayan (GFR düzeyi $>15$ ve $<15 \mathrm{~mL} / \mathrm{dk} / 1,73 \mathrm{~m} 2$ ) hasta bireylerin hasta öğrenim gereksinimlerini, uyku kalitelerini ve emosyonel problemlerini belirlemek, elde edilen sonuçlar ışı̆̆ında konuya ilişkin destek programlarının hazırlanmasına katkı sağlamak amacı ile planlandı.

\section{GEREÇ ve YÖNTEMLER}

Çalışma, tanımlayıcı ve ilişki arayıcı nitelikte olup, Şubat 2017- 2018 tarihleri arasında, Nefroloji kliniğinde yatan ve poliklinikten takip edilen hastalar ile hemodiyaliz merkezinde takip edilen hastalarda gerçekleştirildi. Çalışmada örneklem hesabına gidilmedi, çalışmaya katılmayı kabul eden, gönüllü bireylerin öncelikle yaşı, cinsiyeti, medeni durumu, eğitim durumu gibi sosyodemografik özellikleri ile birlikte GFR değeri kaydedildi. Tüm veriler toplandıktan sonra GFR değerine göre $(15 \mathrm{~mL} / \mathrm{dk} / 1,73 \mathrm{~m} 2>$ GFR ve $15 \mathrm{~mL} / \mathrm{dk} / 1,73 \mathrm{~m} 2<\mathrm{GFR})$ diyalize giren ve girmeyen hasta olarak 2 gruba ayrıldı $(\mathrm{n}=218)$

\section{Veri Toplama Araçları}

Veriler bilgi formu, Pittsburgh Uyku Kalite İndeksi (PUKİ), Hasta Öğrenim Gereksinimleri Ölçeği (HÖGÖ) ve Hastane Anksiyete Depresyon (HAD) Ölçeği formları kullanılarak toplandı. Bilgi formu araştırmacılar tarafından ilgili literatür doğrultusunda 15 maddeden oluştu (yaş, eğitim, cinsiyet vb...)..$^{2,17-19}$ 


\section{Pittsburgh Uyku Kalite İndeksi}

(Pittsburgh Sleep Quality Index-PUKİ):

1991 yılında Buysse ve arkadaşları tarafından geliştiren ölçeğin, ülkemizde güvenilirliği ve geçerliliği Ağargün ve arkadaşları tarafından yapıld..$^{20,21}$ Ölçeğinin puanlanan 18 sorusu 7 bileșenden oluşmaktadır. Bu bileșenler; öznel uyku kalitesi, uyku latensi, uyku süresi, alışlmış uyku etkinliği, uyku bozukluğu, uyku ilacı kullanımı ve gündüz uyku işlev bozukluğu başlıklarında oluşmaktadır. Her bir soru 0-3 puan üzerinden değerlendirilerek, 7 bileşenin toplam puanı ölçek toplam puanı olarak hesaplanır. Toplam puan 0-21 arasında değişir. Toplam puanın 5 ve 5 'ten büyük olması "kötü uyku kalitesini" göstermektedir. Ölçeğin çalışmamızda cronbach alpha iç tutarlılık katsayısı 0.64 olarak saptanmıştır.

\section{Hasta Öğrenim Gereksinimleri Ölçeği-HÖGÖ:}

Ölçek Bubela ve ark. (1990) tarafından geliştirdi ve Türkiye’de ki geçerlilik güvenirliliği Çatal ve Dicle (2008) tarafından yapıldı. ${ }^{14,22}$ Ölçek, toplam 50 madde ve 7 alt boyut (ilaçlar, yaşam aktiviteleri, toplum ve izlem, duruma ilişkin duygular, tedavi ve komplikasyonlar, yaşam kalitesi, cilt bakımı) oluşmaktadır. Ölçeğin değerlendirilmesi, alt boyut ve ölçek toplam puanı üzerinden yapılmaktadır. Elde edilen toplam puan 50-250 arasında değişmekte, alt boyutlar soru sayısına bölünerek 1 ve 5 arası önemlilik düzeyi belirlenmektedir. Yüksek puan; öğrenim gereksiniminin fazla olduğunu göstermektedir. Çalışmamızda ölçeğin alt boyutlarının cronbach alpha değeri 0.772 ile 0.924 arasında değiștiği, toplam değerin ise 0.801 ile güvenilir aralıkta olduğu saptanmıştır.

\section{Hastane Anksiyete Depresyon (HAD) Ölçeği:}

Zigmond ve Snaith tarafından geliştirilen ölçeğin Türkçe geçerlilik güvenilirliği ise Aydemir ve arkadaşları tarafından yapıldı. Ölçek bedensel hastalığı olanlarda emosyonel durum değerlendirmesi sağlamaktadır. 7’si depresyon (çift sayılar), 7'si anksiyete (tek sayılar) belirtilerini araştıran toplam 14 maddeden oluşmaktadır. Yanıtlar dörtlü likert biçiminde değerlendirilmektedir ve 0-3 arasında puanlan- maktadır. Anksiyete alt ölçeği için kesme puanı 10, depresyon alt ölçeği için ise 7 olup, bu puanların üzerinde puan alanlar risk altında olarak değerlendirilirler. ${ }^{23,24}$ Ölçeğin çalışmamızda cronbach alpha iç tutarlılık katsayısı 0.879 olarak saptanmıştır.

\section{Veri Toplama}

Veriler, hasta bireylerle ile yüz yüze görüşülerek toplandı. Yapılan işlemin standartizasyonu için; çalışmaya başlamadan önce 10 birey ile ön uygulama yapıldı, sonrasında çalışma süreci tekrar revize edilerek $15 \mathrm{dk}$ süren seanslar ile uyguland.

\section{İstatistiksel Analiz}

Sürekli değişken normal dağılıma uymadığı için medyan ve çeyrekler arası aralık (interquartile range- IQR) ile gösterildi. Kategorik değişkenler frekans ve yüzde olarak özetlendi. Ölçek hesaplamalarında Cronbach’n Alfa değerleri ve puan ortalamaları verildi. Gözlemlenen verilerin normal dağılımını doğrulamak için Kolmogorov-Smirnov testi kullanıldı. GFR'yi etkileyen risk faktörlerini belirlemek için kolerasyon analizi, arkasından ilişki görülen parametrelerin etki düzeyinin belirlenmesi için regresyon analizi uygulanmıştır. Bütün istatistiksel analizlerde IBM SPSS Statistics 21 versiyonu kullanıld 1 ve $\mathrm{p}<0,05$ anlamlı olarak değerlendirildi.

\section{Etik Konular}

Çalışmaya başlamadan önce örneklemin toplanacağı kurum yönetiminden ve Sakarya Üniversitesi Tip Fakültesi Etik Kurulu’ndan (18.02.2017-71522473/050.01.04/51) yazılı izin alındı. Ayrıca araştırmanın örneklemini oluşturacak bireylere çalışmanın amacı, süresi ve kendilerinden ne beklenildiği açıklanarak isteklilik, gönüllülük ilkesi ışı̆̆ında araştırmaya katılmaları için bilgilendirilmiş olur alındı.

\section{BULGULAR}

Çalışmaya katılan bireylerin GFR'ye göre gruplandırılmış sosyodemografik dağılımları tablo 1'de gösterilmiştir. Bireylerin çoğunluğunun sırasıyla erkek (15>GFR olan 
grupta \%52.9- GFR $<15$ olan grupta $\% 53.8)$, evli (15>GFR olan grupta \%80.4- GFR $<15$ olan grupta \%85), çalışmadiğ 1 (15>GFR olan grupta \%92.8- GFR<15 olan grupta \%61.3), ilkokul mezununu (15>GFR olan grupta \%70.3GFR $<15$ olan grupta \%43.8) ve ek bir rahatsızlığının olduğu (15>GFR olan grupta \% 47.1- GFR $<15$ olan grupta \% 58.8) görüldü (Tablo 1).

\begin{tabular}{|c|c|c|c|}
\hline \multicolumn{4}{|c|}{ Tablo 1: Hastaların sosyodemografik dağılımı } \\
\hline \multicolumn{2}{|l|}{ Değişkenler } & $15>$ GFR & $15<\mathrm{GFR}$ \\
\hline \multicolumn{2}{|l|}{ Yaş (yıl \pm SS) } & $61.67 \pm 12.06$ & $50.75 \pm 14.84$ \\
\hline \multicolumn{2}{|c|}{ Hastalık Süresi (yıl \pm SS) } & $6.71 \pm 4.96$ & $5.78 \pm 4.27$ \\
\hline \multicolumn{2}{|c|}{$\begin{array}{l}\text { Diyalize Ne Zaman Başladığı? } \\
\text { (yıl } \pm \text { SS) }\end{array}$} & $5.87 \pm 4.64$ & - \\
\hline \multicolumn{2}{|c|}{ Diyaliz Sıklığ 1 (gün \pm SS) } & $2.27 \pm 1.06$ & - \\
\hline \multicolumn{2}{|c|}{ Diyaliz Süresi (dakika \pm SS) } & $128.64 \pm 198.80$ & - \\
\hline \multirow{2}{*}{ Cinsiyet (n;\%) } & Erkek & $73 ; 52.9 \%$ & $43 ; 53.8 \%$ \\
\hline & Kadin & $65 ; 47.1 \%$ & $37 ; 46.2 \%$ \\
\hline \multirow{2}{*}{$\begin{array}{l}\text { Medeni } \\
\text { Durum }(n ; \%)\end{array}$} & Bekar & $27 ; 19.6 \%$ & $12 ; 15.0 \%$ \\
\hline & Evli & $111 ; 80.4 \%$ & $68 ; 85.0 \%$ \\
\hline \multirow{2}{*}{$\begin{array}{l}\text { Çalışma } \\
\text { Durumu (n;\%) }\end{array}$} & Evet & $10 ; 7.2 \%$ & $31 ; 38.8 \%$ \\
\hline & Hayır & $128 ; 92.8 \%$ & $49 ; 61.3 \%$ \\
\hline \multirow{4}{*}{$\begin{array}{l}\text { Eğitim } \\
\text { Durumu (n;\%) }\end{array}$} & Okuryazar değil & $35 ; 25.4 \%$ & $9 ; 11.3 \%$ \\
\hline & $\begin{array}{l}\text { Okur yazar-il- } \\
\text { kokul }\end{array}$ & $97 ; 70.3 \%$ & $35 ; 43.8 \%$ \\
\hline & $\begin{array}{l}\text { Ortaöğre- } \\
\text { tim-lise }\end{array}$ & $6 ; 4.3 \%$ & $24 ; 30.0 \%$ \\
\hline & Lisans & $0 ; 0.0 \%$ & $12 ; 15.0 \%$ \\
\hline \multirow{2}{*}{$\begin{array}{l}\text { Komorbid } \\
\text { Hastalık (n;\%) }\end{array}$} & Evet & $65 ; 47.1 \%$ & $47 ; 58.8 \%$ \\
\hline & Hayır & $73 ; 52.9 \%$ & $33 ; 41.3 \%$ \\
\hline
\end{tabular}

15>GFR olan bireylerin \%21.7'sinde ( $n=30)$ HAD-A (kesme puanı=10), \%39.1'inde ( $\mathrm{n}=54)$ HAD-D (kesme pua$\mathrm{n} 1=7)$ eşik seviyesinin üzerinde iken, $15<$ GFR bireylerin \%91.3'ünde ( $\mathrm{n}=73$ ) HAD-A, \%95.0'ında ( $\mathrm{n}=76$ ) HAD-D eşik seviyesinin üzerinde idi. 15>GFR olan bireylerin HAD-A 4.00-8.0, HAD-D 5.00-5.0 iken, $15<$ GFR bireylerin HAD-A 17.00-6.7, HAD-D 15.50-4.0 idi.

HÖGÖ puan ortalamalarına baktığımızda 15>GFR bireylerde toplam puan 182.00-67.5, alt puanları olan ilaçlar 34.00-10.5, yaşam aktivitesi 36.00-9.5, toplum ve izlem
21.00-12.5, duygular 18.00-11.0, tedavi ve komplikasyonlar 35.00-15.0, yaşam kalitesi 34.50-11.0 ve cilt bakımı 21.00-8.0 idi. $15<$ GFR bireylerde ise; toplam puan 195.50 41.5, alt puanları olan ilaçlar 31.50-7.7, yaşam aktivitesi 34.0-10.0, toplum ve izlem 23.00-6.0, duygular19.00-5.0, tedavi ve komplikasyonlar 35.00-7.7, yaşam kalitesi 32.008.0 ve cilt bakımı 32.00-4.7 idi.

PUKİ toplam puanına cut-off değeri olan 5 puanına göre baktığımızda (0-5=iyi, 5 ve üstü=kötü) 15>GFR olan bireylerin \%85.5'inin $(\mathrm{n}=118), 15<\mathrm{GFR}$ ise \%100'ünün uyku kalitesinin kötü olduğu belirlendi. Araştırmaya katılan bireylerin PUKİ alt bileşenleri puan ortalamaları (En $\mathrm{az}=0$, En fazla=3) incelendiğinde; $15>\mathrm{GFR}$ olan bireylerin Median-IQR değeri Bileşen 1 (Öznel Uyku Kalitesi) için 1.00-1.00, Bileşen 2 (Uyku Latensi) 1.00-2.00, Bileşen 3 (Uyku Süresi) 1.00-2.00, Bileşen 4 (Alışılmış Uyku Etkinliği) 3.00-0.0, Bileşen 5 (Uyku Bozukluğu) 1.00-1.00, Bileşen 6 (Uyku İlacı Kullanımı) 0.00-1.00, Bileşen 7 (Gündüz Uyku İşlev Bozukluğu) puan ortalamasının 0.00-1.00 olduğu saptandı. $15<$ GFR olan bireylerin Median-IQR değeri Bileşen 1 (Öznel Uyku Kalitesi) için 2.00-1.00, Bileşen 2 (Uyku Latensi) 1.00-1.00, Bileşen 3 (Uyku Süresi) 5.00-1.00, Bileşen 4 (Alışılmış Uyku Etkinliği) 0.00-0.00, Bileşen 5 (Uyku Bozukluğu) 2.00-1.00, Bileşen 6 (Uyku İlacı Kullanımı) 0.00-1.00, Bileşen 7 (Gündüz Uyku İşlev Bozukluğu) puan ortalamasının 2.00-1.00 olduğu saptand (Tablo 2).

Ölçekler ve bazı değişkenler ile GFR arasındaki ilişkiler, pearson korelasyon katsayısı ile incelenmiştir. Bu amaçla yapılan istatistiksel analiz sonuçlarına göre bireylerin GFR değeri ile HAD-A ile HAD-D arasında anlamlı, pozitif yönde ve yüksek düzeyde bir ilişki olduğu ( $r=0.712$; $\mathrm{p}=<0.001, \mathrm{r}=0.704 ; \mathrm{p}=<0.05$ ) görüldü (Tablo 3).

İlişkili çıkan GFR, HAD-A ve HAD-D düzeylerinin tahmini ve etki düzeyi için varyans analizlerinde istatistiksel olarak anlamlılık tespit edilen bağımsız değişkenle çoklu regresyon analizi yürütülerek bir model oluşturuldu. 
Modele istatistiksel olarak anlamlı etkisi olan bağımsız değişkenler HAD-A ve HAD-D değişkenleriydi (FHA$\mathrm{DA}-\mathrm{HADD}=112.324, \mathrm{p}<0.001, \mathrm{R} 2=0.511$, Durbin Watson=1,393). Regresyon analizinde GFR değeri HAD-A ve HAD-D'nin artmasinda \%50'sinden sorumlu, tahmin edici faktörler olup tablo 4'de çoklu regresyon analizi sonucundan elde edilen modelin detayları gösterilmektedir. Çoklu regresyon modeli $=8.704+0.826^{\star} \mathrm{HAD}-\mathrm{A}+0.8968^{\star} \mathrm{HAD}-\mathrm{D}$

\begin{tabular}{|c|c|c|}
\hline & $\begin{array}{c}\text { 15>GFR } \\
\text { Median-IQR } \\
(\text { Min-Max })\end{array}$ & $\begin{array}{c}15<\mathrm{GFR} \\
\text { Median-IQR } \\
(\text { Min-Max) }\end{array}$ \\
\hline HADA & $4.00-8.0(0-18)$ & $17.00-6.7(5-23)$ \\
\hline HADD & $5.00-5.0(0-19)$ & $15.50-4.0(5-23)$ \\
\hline HÖGÖ İlaçlar & $34.00-10.5(17-40)$ & $31.50-7.7(22-40)$ \\
\hline $\begin{array}{l}\text { HÖGÖ Yaşam Ak- } \\
\text { tivitesi }\end{array}$ & $36.00-9.5(17-45)$ & $34.0-10.0 \quad(21-45)$ \\
\hline $\begin{array}{l}\text { HÖGÖ Toplum ve } \\
\text { İzlem }\end{array}$ & $21.00-12.5(11-30)$ & $23.00-6.0(14-30)$ \\
\hline HÖGÖ Duygular & $18.00-11.0(7-25)$ & $19.00-5.0(10-25)$ \\
\hline $\begin{array}{l}\text { HÖGÖ Tedavi ve } \\
\text { Komp. }\end{array}$ & $35.00-15.0(20-45)$ & $35.00-7.7(24-45)$ \\
\hline HÖHÖ Yaşam Kalitesi & $34.50-11.0(15-90)$ & $32.00-8.0(20-40)$ \\
\hline HÖGÖ Cilt Bakımı & $21.00-8.0(7-25)$ & $32.00-4.7(20-40)$ \\
\hline HÖGÖ toplam & $182.00-67.5(114-300)$ & $195.50-41.5(131-250)$ \\
\hline $\begin{array}{l}\text { PUKİ Öznel Uyku } \\
\text { Kalitesi }\end{array}$ & $1.00-1.00(0-3)$ & $2.00-1.00(1-4)$ \\
\hline PUKİ Uyku Latensi & $1.00-2.00(0-3)$ & $1.00-1.00(1-3)$ \\
\hline PUKİ Uyku Süresi & $1.00-2.00(0-3)$ & $5.00-1.00(0-3)$ \\
\hline $\begin{array}{l}\text { PUKİ Alıșılmıș Uyku } \\
\text { Etkinliği }\end{array}$ & $3.00-0.0(0-3)$ & $0.00-0.00(0-0)$ \\
\hline PUKİ Uyku Bozukluğu & $1.00-1.00(0-3)$ & $2.00-1.00(2-2)$ \\
\hline PUKİ Uyku İlacı & $0.00-1.00(0-3)$ & $0.00-1.00(0-0)$ \\
\hline $\begin{array}{l}\text { PUKİ Gündüz İşlev } \\
\text { Bozukluğu }\end{array}$ & $0.00-1.00(0-3)$ & $2.00-1.00(2-2)$ \\
\hline PUKİ Toplam & $7.50-5.25(2-18)$ & $8.00-2.00(6-12)$ \\
\hline \multicolumn{3}{|c|}{$\begin{array}{l}\text { HAD-A: Hastane anksiyete depresyon skalası anksiyete alt ölçeği, HAD-D: } \\
\text { Hastane anksiyete depresyon skalası depresyon alt ölçeği, HÖGÖ: Hasta } \\
\text { Öğrenim Gereksinimleri Ölçeği , PUKİ: Pittsburgh Uyku Kalite İndeksi. } \\
\text { IQR: çeyrekler arası aralık (interquartile range). GFR: Glomerular filtra- } \\
\text { syon değeri. }\end{array}$} \\
\hline
\end{tabular}

Tablo 3. HÖGÖ, PUKI, HAD-A ve HAD-D puan ortalamalari ile GFR değeri ilişkisi $(n=218)$

\begin{tabular}{|l|c|c|}
\hline \multirow{2}{*}{ Ölçekler } & \multicolumn{2}{|c|}{ GFR Değeri } \\
\cline { 2 - 3 } & $\mathbf{r}$ & $\mathbf{p}$ \\
\hline HÖGÖ Toplam & 0.026 & 0.700 \\
\hline PUKİ Toplam & 0.081 & 0.231 \\
\hline HAD-A & 0.712 & $<\mathbf{0 . 0 0 1}$ \\
\hline HAD-D & 0.704 & $<\mathbf{0 . 0 0 1}$ \\
\hline
\end{tabular}

r: Pearson's korelasyon. $\mathrm{p}<0.05$ anlamlılık olarak alındı. IQR: çeyrekler arası aralık (interquartile range). GFR: Glomerular filtrasyon değeri.

HAD-A: Hastane anksiyete depresyon skalası anksiyete alt ölçeği, HAD-D:

Hastane anksiyete depresyon skalası depresyon alt ölçeği, HÖGÖ: Hasta

Öğrenim Gereksinimleri Ölçeği, PUKİ: Pittsburgh Uyku Kalite İndeksi.

\begin{tabular}{|c|c|c|c|c|c|c|c|c|}
\hline \multirow{2}{*}{ 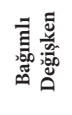 } & \multirow{2}{*}{ 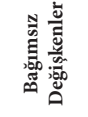 } & \multirow{2}{*}{$\beta$} & \multirow{2}{*}{ 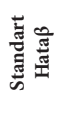 } & \multicolumn{2}{|c|}{$95 \%$ CI of $\beta$} & \multirow{2}{*}{$t$} & \multirow{2}{*}{$\mathbf{F}$} & \multirow{2}{*}{$\mathbf{p}$} \\
\hline & & & & Alt & Üst & & & \\
\hline \multirow{3}{*}{ 舀 䓌 } & Constant & 8.704 & 1.314 & 6.114 & 11.295 & 6.623 & \multirow{3}{*}{ 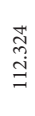 } & $<0.001^{\star}$ \\
\hline & HAD-A & 0.826 & 0.165 & 0.501 & 1.151 & 5.013 & & $<0.001^{\star}$ \\
\hline & HAD-D & 0.896 & 0.197 & 0.507 & 1.285 & 4.536 & & $<0.001^{\star}$ \\
\hline \multicolumn{9}{|c|}{$\begin{array}{l}\mathrm{R}=0.715 / \mathrm{R} 2=0.511 / \text { Düzeltilmiş } \mathrm{R} 2=0.506 \\
{ }^{*} \mathrm{p}<.001 \text { düzeyinde anlamlıdır. GFR: Glomerular filtrasyon değeri. HAD-A: Hastane } \\
\text { anksiyete depresyon skalası anksiyete alt ölçeği, HAD-D: Hastane anksiyete depresyon } \\
\text { skalası depresyon alt ölçeği }\end{array}$} \\
\hline
\end{tabular}

\section{TARTIŞMA}

KBY ilerleyici renal fonksiyon kaybı ve diyalizin başlang1cından itibaren kalan renal fonksiyonda sürekli azalmayla kendini gösteren bir hastalıktır. GFR düzeyi $>15$ ve $<15$ $\mathrm{mL} / \mathrm{dk} / 1,73 \mathrm{~m} 2$ olması diyaliz tedavisine başlanmasında karar verici parametre olup mortalite üzerinde de belirleyici olduğu bilinmektedir. ${ }^{25}$ Çalışmamız GFR düzeyine göre ayrılan gruplarının diyaliz tedavisi alma durumunun HAD düzeyi, uyku kalitesi ve öğrenme gereksinimleri üzerindeki etkisini araştırması bakımından ilk olma özelliğine sahiptir.

Çalışmaya dahil olan bireylerin PUKİ toplam puanı 0.231 ve GFR düzeyi düştükçe uyku kalitesinin \%100 olumsuz etkilendiği görüldü. Araştırmanın bu bulgusu literatür bilgisi ile desteklenir nitelikte idi. ${ }^{2,18,26}$ Kusleikaite ve arkadaşlarının PUKİ kullanarak 81 hemodiyaliz hastasında yaptıkları çalışmada uyku kalitesi kötü olanların sıklığının \%67.7 olduğu belirtmiştir. ${ }^{9}$ 
KBY hastaları yaşadıkları uyku problemi sebebi ile gün içinde uykulu olma hali yaşamakta, günlük aktivitelerini gerçekleştirmek için gerekli olan performans ve enerji düzeyi olumsuz etkilenmektedir. ${ }^{18}$ Çalışmamıza benzer şekilde Roumelioti ve arkadaşları ise, GFR düzeyine göre hemodiyaliz hastalarının uyku durumunu incelemiştir. ${ }^{27}$ Çalışmada gündüz aşırı uyku halini bir ölçek ile değerlendiren araştırmacılar, ölçek ile GFR arasında ilişki olduğu sonucuna varmış, ancak çalışma sonucunda böbrek hastalarında uyku değerlendirmesinde gündüz uykusu ölçeğinin tek başına yeterli olmadığını vurgulamıștır. Diyaliz tedavisi alan hastaların ağrı, üremik sendrom, yorgunluk, belirsizlik, korku vb nedenler ile uyku bozuklukları yaşadıkları, uyku sürelerinin azaldığı bilinmektedir., ${ }^{4,10,11} \mathrm{Bu}$ sonuçlara göre, GFR düzeyine bağlı olarak diyaliz tedavisi alma durumunun hastaların uyku kalitesini etkilediği söylenebilir.

Yaşam için gerekli unsurlardan biri olan uyku alışkanlığındaki değişiklik anksiyeteye neden olabilmektedir. Çalışma kapsamına alınan hastaların, GFR hızı azaldıkça, HADA ve HADD düzeyinin yükseldiği saptanmıştır. HAD puanın artması diyaliz tedavisi nedeniyle yaşanabilen üremik veya hormonal eksikliklerin varlığına bağlı olarak gelişen metabolik değişikliklerden kaynaklandığı düşünülmektedir. Çalışmalarda her iki durumun da yaşam kalitesini olumsuz etkilediği ve dolayısıyla anksiyete ve depresyon ile ilişkili olduğu gösterilmiştir., ${ }^{3,28}$ Ebben ve arkadaşları 152 hemodiyaliz hastası ile yaptıkları çalışmada, 6 ay takip sonrası bireylerin hemoglobin düzeyinin düşük olması ile emosyonel problemler gibi komorbid hastalıkların ilişkili olduğu sonucuna varmıştır. ${ }^{29}$ Başka bir çalışmada da kronik böbrek yetmezliği olan hastaların anksiyete ve depresyon riskinin yüksek olduğu sonucunu elde edilmiştir. ${ }^{30}$

Hastaların eğitim gereksinimlerini saptamak için HÖGÖ kullanılmıştır. Çalışmaya dahil olan bireylerin toplam puanı 0.700 idi. GFR düzeyi düştükçe HÖGÖ puanının da yükseldiği görüldü. Kronik hastalıklarda hastalık hakkındaki bilgi eksikliği olumsuz yaşam kalitesine, anksiyeteye ve beraberinde uyku problemlerine neden olmaktadir. Bunu destekleyen araştırmalar da mevcuttur. ${ }^{6,16,19}$ Curtin ve arkadaşları ve Wells çalışmalarında KBY hastalarına yapılacak planlı eğitimin fiziksel ve emosyonel sağlık durumu ve tedavi başarısında olumlu katkı sağlayacağını belirtmişlerdi. ${ }^{17,19} \mathrm{Bu}$ doğrultuda KBY ve özellikle diyaliz tedavisi alan bireylerin öğrenim gereksinimlerinin karşılanmasının tedavinin başarısı ve yönetiminde önemli role sahip olduğu görülmektedir.

Çalışmada GFR değerinin bir puanlık yükselmesi, HAD-A ve $\mathrm{HAD}-\mathrm{D}$ değerlerinin $\% 50$ oranında yükselmesinin anlamlı bir şekilde tahmin edebildiğini, kestirdiğini göstermektedir. KBY'de önemli bir değişken olan GFR düzeyi, bireyin diyaliz tedavisine karar verilmesinde de rol oynamaktadır. Bu nedenle GFR durumuna göre ayrilan bireylerin diyalize girme durumunun $(\mathrm{GFR}>15$, GFR $<15)$ hastane anksiyete ve depresyon düzeyini kestirmede güçlü bir değişken olduğu söylenebilir. Kronik böbrek yetmezliği olan hastalarda hastalığın evresi, süre ve tedavi şekli ile ilgili olarak uyum problemleri, davranışsal değişimler, anksiyete, depresyon gibi komplikasyonlar görülmesinde kuşkusuz önemli bir etmendir. ${ }^{12,8}$ Başka bir çalışmada ise depresyonun diyalizden ayrılma belirtisi olduğu bildirilmektedir. $^{30}$

Kronik hastalıkların ve hemodiyaliz hastalarının uyku kalitesini değerlendiren ve anksiyete durumunu saptayan araştırmalar mevcuttur; fakat uyku, anksiyete ve öğrenim gereksinimin GFR ile ilişkisini inceleyen araştırmaya rastlanmamıştır. KBY olan ve GFR'si düşüş gösteren hastalar psikiyatrik değerlendirmeye alınmalı, gerekli durumlarda psikiyatrik tedavinin başlatılması sağlanmalıdır. Bunun hastaların psikososyal uyumlarını kolaylaştırması, tedavinin başarısını artırması, hastanın yaşam kalitesini yükseltmesi muhtemeldir.

\section{SONUÇ ve ÖNERİLER}

Bu çalışmada sonuç olarak GFR düzeyi dolayısıyla diyalize girme durumu ile uyku kalitesi, öğrenim gereksinimleri ve 
HAD puan ortalamalarının olumsuz etkilendiği, HAD düzeyi ile arasında anlamlı fark oluşturan bir ilişkinin olduğu bulundu. Özellikle diyaliz tedavisi almanın hastalarda uyku sorunlarının daha sık rastlanması nedeniyle, kalitesinin bozulduğu, fiziksel bulgular ve tedavi sürecinde emosyonel problemlerin yaşandığı ve bu nedenle sağlık bakımı yaklaşımlarının ona göre düzenlenmesi gerektiği görüldü. $\mathrm{Bu}$ araştırmanın daha geniş popülasyonla ve daha fazla bağımsız değişkenler ile yapılması önerilebilir.

\section{Sinirliliklar}

Tanımlayıcı ve ilişki arayıcı nitelikteki araştırmada, çalışma yönteminin doğası gereği neden sonuç ilişkisi kurulamaması en büyük sınırlılıktır. Çalışma örnekleminin bulunduğu tedavi ortamı ve fiziksel kısıtlılıkları nedeniyle kendi beyanlarına dayalı toplanmaya çalışılan öznel verilerde sınırlılık yaratmaktadır. Çalışma konusunu içeren literatür desteğinin az olması ve son olarak çoklu regresyon modelinde 4 veriye karşılık bir bağımsız değişken olması istatiksel olarak başka bir sınırlılık yaratmaktadır.

\section{Yazar Katkıları:}

Çalışmanın dizayn: ÖD. Veri toplama ve analizi: ÖD, DSG, SS, KEÖ. Makalenin hazırlanması: ÖD, DSG. Makalenin yayınlanması: ÖD.

\section{Finansal Destek ve Çıkar Bildirimi:}

Çalışmada tüm araştırmacılar herhangi bir finansal destek ve çıkar ilişkisi bulunmadığımı, herhangi bir kurum ya da kuruluş tarafından desteklenmediğini ve kendi olanakları ile gerçekleştirildiğini beyan eder. 
Sakarya Tip Dergisi 2019;9(3):412-419

KöKÇÜ ve Ark., Glomerüler Filtrasyon Değeri Yordama Gücü

Kaynaklar

1. Çelik C, Acar T. Kronik hemodiyaliz hastalarında depresyon ve anksiyete düzeylerininçeșitli değişkenlere göre incelenmesi. Furat Tip Dergisi 2007;12(1):23-27.

2. Bilgic A, Akgul A, Sezer S, Arat Z, Ozdemir FN, Haberal M. Nutritional status anddepression, sleep disorder, and quality of life in hemodialysis patients. Journal of RenalNutrition 2007: 17(6); 381-388.

3. Teles F, Albuquerque LA, Guedes Lins IKF, Medrado PC, Pedrosa Costa AF. Quality oflife and depression in haemodialysis patients. Psychology, Health $\backsim$ Medicine 2018; 2:10.https:// doi.org/10.1080/13548506.2018.1469779

4. Sandwijk MS, Arashi DA, Hare FM, Torren R, Kersten MJ, Bijlsma JA, Berge IJM, Bemelman FJ. Fatigue, anxiety, depression and quality of life in kidney transplant recipients, haemodialysis patients, patients with a haematological malignancy and healthy controls. Nephrol Dial Transplant 2018;1-5. doi: 10.1093/ndt/gfy103

5. Szeifert L, Molnar MZ, Ambrus C ve ark. Symptoms of depression in kidney transplantrecipients: a cross-sectional study. Am J Kidney Dis 2010; 55: 132-140

6. Alikari V, Tsironi M, Matziou V, Tzavella F, Fradelos E, Zyga S. Reliability and validityof the kidney disease questionnaire among greek patients undergoing hemodialysis.American Journal of Nursing Science 2018; 7(3-1): 97-102. doi:10.11648/j.ajns.s.2018070301.24

7. Finnegan-John J, ve Thomas VJ. The psychosocial experience of patients withend-stage renal disease and its impact on quality of life: Findings from a needs assessment toshape a service. ISRN Nephrology 2013; 308986. 1-8. doi:10.5402/2013/308986

8. Teles F, Azevedo VF, Miranda CT, Miranda MP, Teixeira Mdo C, ve Elias RM. Depression in hemodialysis patients: The role of dialysis shift. Clinics (Sao Paulo) 2014; 69(3): 198-202. doi:10.6061/clinics/2014;3:10

9. Kusleikaite N, Bumblyte IA, Razukeviciene L, Sedlickaite D, Rinkünas K. Sleep disorders and quality of life in patients on hemodialysis. Medicina (Kaunas, Lithuania) 2005; 41:6974 .

10. Chu G, Choi P, McDonald VM. Sleep disturbance and sleep-disordered breathing inhemodialysis patients. Seminars in Dialysis 2018; 31:48-58. dot:10.1111/sdi.12617

11. Harris TJ, Nazir R, Khetpal P, Peterson RA, Chava P, Patel SS, Kimmel PL. Pain, sleep disturbance and survival in hemodialysis patients. Nephrol Dial Transplant 2012;27:758-765.

12. Iliescu EA, Coo H, McMurray MH, Meers CL, Quinn MM, Singer MA, Hopman WM.quality of sleep and health-related quality of life in haemodialysis patients. Nephrol DialTransplant 2003;18:126-32.

13. Mutlu E. hemodiyaliz hastalarının sosyo-demografik özellikleri, sosyal destek kaynakları ve hastalik sürecinin benlik saygısına etkisi. Yüksek Lisans Tezi, HacettepeÜniversitesi, Sosyal Bilimler Enstitüsü, Ankara, 2007 (Yayınlanmamış tez).

14. Çatal E, Dicle A. Hasta Öğrenim Gereksinimleri Ölçeğinin Türkiye’de geçerlikve güvenirlik çalş̧ması. Dokuz Eylül Üniversitesi Hemşirelik Yüksekokulu Dergisi 2008;1(1): 19-32.

15. Howland RH. What should patients be told about their medications? Journal of Psychosocial Nursing 2009; 47(2): 17-20.

16. Doğu Ö, Kaya H, Gündüz H, ve Parlak Z. Web based distance learningsuggestion in training and consultation for myocardial infarction patients. MN Kardiyoloji 2015; 22(4); 217-22.

17. Curtin RB, Sitter DCB, Schatell D, Chewning BA. Self-management, knowledge, andfunctioning and well-being of patients on hemodialysis. Nephrology Nursing Journal 2004;31(4): 378-396.

18. Köse E. Hemodiyaliz hastalarının beslenme durumları ve uyku kalitesi arasındaki ilișki. Harran Üniversitesi Sağllk Bilimleri Enstitüsü Hemșirelik Anabilim Dalı Yüksek LisansTezi Sanlıurfa 2009 (Yayınlanmamıș tez).

19. Wells JR. Hemodialysis knowledge and medical adherence in African Americansdiagnosed with end stage renal disease: results of an educational intervention. Nephrol NursJ 2011; 38:155-162.

20. Agargün MY, Kara H, Anlar O. Pittsburgh Uyku Kalite İndeksinin geçerliliği vegüvenirliği Türk Psikiyatri Dergisi 1996; 7, 107-115.

21. Buysse DJ, Reynolds CF, Monk TH, Hoch CC, Yeager AL, Kupfer DJ. Quantification of subjective sleep quality in healthy elderly men and women using the Pittsburgh Sleep Quality Index (PSQI). Sleep 1991; 14(4), 331-338.

22. Bubela N, Galloway S, McCay E, McKibbon A, Nagle L, Pringle D, Ross E, Shamian J. The patient learning needs scale: reliability and validity. Journal Advanced Nursing 1990;15: 1181-1187.

23. Aydemir $O$, Güvenir T. Validity and reliability of Turkish version of hospital anxiety and depression scale. Turk J Psychiatry 1997;8:280-287.

24. Zigmond AS, Snaith PR. The hospital anxiety and depression scale. Acta Psychiatr Scand 1983;67:361-70.

25. Szeto CC, Wong TY, Chow KM, Leung CB, Law MC, Li PK. Independent effects ofrenal and peritoneal clearances on the mortality of peritoneal dialys is patients. Perit Dial Int2004; 24: 58-64.

26. Pai MF, Hsu SP,Yang SY, Ho TL. Sleep disturbance in chronic hemodialysis patients: thimpact of depression and anemia. Ren Fail 2007; 29(6): 673-677.

27. Roumelioti ME, Buysse DJ, Sanders MH, Strollo P, Newman AB, Unruh ML. Sleepdisordered breathing and excessive daytime sleepiness in chronic kidney disease andhemodialysis. Clin J Am Soc Nephrol. 2011;6:986-994

28. Zyoud SH, Daraghmeh DN, Mezyed DO, Khdeir RL, Sawafta MN, Ayaseh NA, Tabeeb GH, Sweileh WM, Awang R, Al-Jabi SW. Factors affecting quality of life in patients on haemodialysis: A cross-sectional study from Palestine. BMC Nephrology 2016; 17. doi:10.1186/ s12882-016-0257-z

29. Ebben JP, Gilbertson DT, Foley RN, Collins AJ. Hemoglobin level variability: Associations with comorbidity, intercurrent events, and hospitalizations. Clinical Journal of the American Society of Nephrology 2006;1(6): 1205-1210. doi:10.2215/cjn.01110306

30. McDade-Montez EA, Christensen AJ, Cvengros JA, ve ark. The role of depressionsymptoms in dialysis with drawal. Health Psychol. 2006; 25: 198- 204. 